\title{
Prick Me, I Must Be Dreaming: Non-Invasive Glucose Monitoring in Diabetes
}

\author{
Tamar Lin* \\ Integrity Applications Ltd., Ashdod, Israel \\ Submission: August 28, 2017; Published: August 28, 2017 \\ *Corresponding author: Tamar Lin, Integrity Applications Ltd. 19 Ha’Yahalomim st. Ashdod, Israel, Tel: 972 -8-675-7878; \\ Email: tamarl@integrity-app.com
}

\section{Opinion}

Diabetes mellitus is an epidemic disease affecting approximately 415 million people worldwide [1]. Self-monitoring of blood glucose (SMBG) has an integral role in diabetes management, since it helps achieve and maintain glycemic control which may reduce diabetes-related complications [2,3] and their associated costs [4]. For most people with type 1 diabetes or insulin-treated type 2 diabetes, SMBG is recommended three or more times daily [5-7]. The recommendations for how often people with non-insulin type 2 diabetes should test their glucose levels are based upon individual factors such as type of treatment (diet, oral medication), level of glycated hemoglobin (HbA1C), and treatment goals. Notably, in people with non-insulin type 2, the International Diabetes Federation (IDF) endorses SMBG as part of ongoing diabetes self-management to assist in better understanding the disease and provide a means to actively and effectively participate in its control and treatment (modify behavioral and pharmacological interventions) [8]. SMBG is also critical to the prevention of type 2 diabetes among individuals with prediabetes [9]. Moreover, glucose monitoring may also be useful in cases of stable glucose levels, as a surveillance tool during periods of stress or if patients are being introduced to a new treatment, nutritional plan and/or exercise regime, or entering a new life experience.

Despite the clinical benefits of glucose self-monitoring, patient compliance to glucose self-monitoring is limited $[10,11]$. The low adherence mainly results from the discomfort and pain associated with skin lancing and the complexity of test procedures [12-14]. Non-invasive glucose monitoring devices for home use aim to overcome the barriers of current invasive glucose monitoring methods by offering a simple, painless and convenient mean to measure glucose levels. The great deal of efforts that have been dedicated to the development of noninvasive glucose monitoring devices is an indicator of where the field of glucose monitoring is heading. However, to date, most of non-invasive technologies lacked sufficient accuracy and failed to operate over a long period of time $[15,16]$. Since diabetes prevalence increases every year, with a worldwide estimate of 642 million people in 2040 [1], a breakthrough in non-invasive glucose monitoring devices is essential to both improve the quality of life of a substantial population of patients and to significantly reduce the social and economic burden of diabetes.

One major reason that so many devices do not succeed to their expected level, is the fact that they only rely on one technology. The technologies used for non-invasive glucose monitoring include optical, transdermal or thermal techniques, each characterized by advantages and limitations. In general, noninvasive approaches suffer from relatively poor sensitivity and specificity to glucose, since the indirectly measured parameters may be affected from physiological factors other than glucose as well as from environmental or time-dependent factors such as temperature and blood pressure, respectively. However, utilizing parallel monitoring of more than one parameter using multisensor systems may improve the overall accuracy, since the combination of different factors provides a more comprehensive evaluation of blood glucose by covering various physical and chemical tissue parameters. For example, a widely studied technology for non-invasive glucose monitoring is near infrared (NIR) spectroscopy [17]. Although this technology has been applied in numerous devices during the past 20 years, none of them have reached the market. Nonetheless, it has recently been demonstrated that combining NIR spectroscopy and electrical impedance spectroscopy enables to predict capillary glucose concentrations more accurately than the performance of each techniques individually [18], thus opening a new avenue for the development of new non-invasive glucose monitoring devices.

Accordingly, the approach of integrating several independent glucose-related technologies has been employed in GlucoTrack ${ }^{\circledR}$ (Integrity Applications, Israel). In this non-invasive device glucose levels are measured from the earlobe using ultrasound (acoustic impedance of the tissue), electromagnetic properties 
(tissue electrical impedance), and thermal changes (heat capacity of the tissue) $[19,20]$. The three independent readings are combined together by a proprietary algorithm, which calculates their weighted average and provides the related tissue glucose value. The translation of the measured signals into glucose readings is achieved by individual calibration, which also reduces the impact of quasi-stable components in the earlobe tissue.

Gluco Track is a Conformité Européene (CE) certified non-invasive glucose monitoring device, intended for people with type 2 diabetes or prediabetes for home and home-alike environments use. Recent clinical studies have demonstrated that glucose assessment from the ear lobe obtained using GlucoTrack has an acceptable accuracy and precision. These results indicate that combining several technologies to non-invasively measure glucose is indeed promising. Furthermore, it has recently been shown that GlucoTrack is easy to use and has high acceptance rates among the diabetes population [21], two additional key factors for successful market penetration. GlucoTrack, thus, introduces a truly non-invasive device that offers people with type 2 diabetes and prediabetes a novel way to painlessly test glucose levels as often as needed with improved quality of life. From a healthcare professional (HCP) perspective, GlucoTrack provides better insights on patients' glucose patterns as well as facilitates medical adherence. This device, therefore, represents a step forward in diabetes management, revolutionizing selfmonitoring of glucose in people with type 2 diabetes.

In conclusion, the increased necessity for new non-invasive glucose monitoring systems that can be actually used in clinical practice reinforces the need to adopt new technological perspectives that will result in more accurate non-invasive glucose monitoring devices, a major goal that has only been partially fulfilled despite decades of technological advancement. The established performance of GlucoTrack points to a potential paradigm shift from the use of one technology to an integrated glucose prediction based on several independent measurements.

\section{References}

1. International Diabetes Federation (IDF) diabetes atlas (2015). Brussels, Belgium: International Diabetes Federation.

2. Diabetes Control and Complications Research Group and others (1993) The effect of intensive treatment of diabetes on the development and progression of long-term complications in insulin-dependent diabetes mellitus. N Engl J Med 329: 977-986.

3. (1998) Intensive blood-glucose control with sulphonylureas or insulin compared with conventional treatment and risk of complications in patients with type 2 diabetes (UKPDS 33). The Lancet 352(9131): 837-853.

4. Williams R, L Van Gaal and C Lucioni (2002). Assessing the impact of complications on the costs of Type II diabetes. Diabetologia 45: S13-S17.
5. Bergenstal RM, Gavin JR (2005) The role of self-monitoring of blood glucose in the care of people with diabetes: report of a global consensus conference. Am J Med 118(Suppl 9A): 1-6.

6. Berard LD, Blumer I, Houlden R, Miller D, Woo V (2013) Monitoring Glycemic Control. Can J Diabetes 37(Suppl 1): S35-S39.

7. American Diabetes Association (2016). Standards of medical care in diabetes-2016 (Diabetes Care).

8. Gagliardino JJ, Bergenstal R, Colagiuri S, Farmer A, Karter A, et al. (2009) IDF Guideline on self-monitoring of blood glucose in noninsulin treated type 2 diabetes. Int Diabetes Fed IDF Brus Int Diabetes Fed.

9. Hu Z, Qin L, Xu H (2017) One-Year Results of a Synthetic Intervention Model for the Primary Prevention of T2D among Elderly Individuals with Prediabetes in Rural China. Int J Environ Res Public Health 14(4): 417.

10. Brindisi MC, Hahn J, Chiasson JL, Rabasa-Lhoret R (2007) Underutilization of capillary glucose monitoring by type 2 diabetic patients. Diabetes Res Clin Pract 75(1): 123-125.

11. Harris MI, Cowie CC, Howie LJ (1993) Self-monitoring of blood glucose by adults with diabetes in the United States population. Diabetes Care 16(8): 1116-1123.

12. Polonsky WH, Fisher L, Hessler D, Edelman SV (2014) What is so tough about self-monitoring of blood glucose? Perceived obstacles among patients with Type 2 diabetes. Diabet Med 31(1): 40-46.

13. Vincze G, Barner JC, Lopez D (2003) Factors associated with adherence to self-monitoring of blood glucose among persons with diabetes. Diabetes Educ 30(1): 112-125.

14. Wagner J, Malchoff $C$, Abbott $G$ (2005) Invasiveness as a barrier to selfmonitoring of blood glucose in diabetes. Diabetes Technol Ther 7(4): 612-619.

15. Lin T, A Gal, Y Mayzel, K Horman, K Bahartan (2017) Non-Invasive Glucose Monitoring: A Review of Challenges and Recent Advances. Curr Trends Biomed Eng Biosci 6: 1-8.

16. Vashist SK (2012) Non-invasive glucose monitoring technology in diabetes management: A review. Anal Chim Acta 750: 16-27.

17. Salam NABA, Saad M, Manap ZB, Salehuddin F (2016) The Evolution of Non-invasive Blood Glucose Monitoring System for Personal Application. J Telecommun Electron Comput Eng JTEC 8(1): 59-65.

18. Guevara E, FJ González (2010) Joint optical-electrical technique for noninvasive glucose monitoring. Rev Mex Física 56(5): 430-434.

19. Harman-Boehm I, Gal A, Raykhman AM, Zahn JD, Naidis E (2009) Noninvasive glucose monitoring: a novel approach. J Diabetes Sci Technol 3(2): 253-260.

20. Harman-Boehm I, Gal A, Raykhman AM, Naidis E, Mayzel Y (2010) Noninvasive glucose monitoring: increasing accuracy by combination of multi-technology and multi-sensors. J Diabetes Sci Technol 4(3): 583-595.

21. Horman K, Mayzel Y, Gal A, Bahartan K, Drexler A, et al. (2016) Performance and User Experience Evaluation of a Non-Invasive Glucose Monitoring Device. Int J Diabetes Metab Disord 1: 1-7. 
This work is licensed under Creative Commons Attribution 4.0 License

DOI:10.19080/CTBEB.2017.08.555728
Your next submission with Juniper Publishers will reach you the below assets

- Quality Editorial service

- Swift Peer Review

- Reprints availability

- E-prints Service

- Manuscript Podcast for convenient understanding

- Global attainment for your research

- Manuscript accessibility in different formats ( Pdf, E-pub, Full Text, Audio)

- Unceasing customer service

Track the below URL for one-step submission https://juniperpublishers.com/online-submission.php 